\title{
Predisposing Factors to Homosexuality among Men in Kilifi Town- Kenya
}

\author{
Evah Maina ${ }^{1}$, Dennis Butto ${ }^{2, *}$, Mary Murigi ${ }^{2}$ \\ ${ }^{1}$ Department of Medical Services, Kirinyaga University College, Kenya \\ ${ }^{2}$ School of Health Sciences, Kirinyaga University College, Kenya
}

Copyright $\mathrm{O} 2016$ by authors, all rights reserved. Authors agree that this article remains permanently open access under the terms of the Creative Commons Attribution License 4.0 International License

\begin{abstract}
Understanding predisposing factors to homosexuality is important in formulating behavioural interventions targeted to men having sex with men (MSM) who form part of key populations as defined by World Health Organization. A descriptive cross-sectional study utilizing snowballing sampling methodology was conducted to determine predisposing factors to homosexuality in Kilifi town council. The study, which carried out between the months of August and December 2015, included both self-identified and non-self-identified MSM in Kilifi town. Data was collected through self-administered questionnaires, focused group discussions and key informant interviews drawn from healthcare institutions and law enforcement agencies that ensure the safety of MSM in the community. Data was thereafter analysed by descriptive statistics. The findings of this study demonstrated that homosexuality is as a result of socialization rather than biological causes. $66.6 \%$ of respondents cited choice as the reason they were homosexuals. They further described homosexuality as a lifestyle, meaning it's a decision they made. Peer pressure, parental upbringing, family set up, watching pornography, physical and sexual abuse when growing up were other factors mentioned by the respondents. Community involvement and sensitization would be important in reducing the number of boys who convert to homosexuality at some point in life.
\end{abstract}

Keywords Homosexuality, Gay, Kings, Queens

\section{Introduction}

Homosexuality is the term used to refer to people who are romantically attracted, sexual attraction or sexual behaviour between members of the same sex. Homosexuality also refers to the individual sense of personal and social identity based on these attractions, behaviours that express them and membership to a community of individuals that share the beliefs and sexual orientations [1]. Scientists have no consensus as to why people develop certain sexual orientations but biological based theories have been favoured by experts who relate this to genetic predisposition and early uterine development. The common terms for homosexuals are Lesbian for females who have sex with females and gay for men who have sex with men. Many men who have sex with men are in committed same sex relationships and few are bisexual. The number of people who identify themselves as homosexuals is difficult to determine since not many declare this openly, especially in the African set up due to homophobia and heterosexist discrimination [2].

According to Billy [3], men who have sex with men (MSM) was a term coined in 1992 in an attempt to capture a range of male- male sexual behaviours and avoid characterization of men engaging in these behaviours by sexual orientation (homosexual, heterosexual, bisexual or gay) or gender identity (male, female, transgender, queer). MSM includes gay- identified men, heterosexually identified men who have sex with men, bisexual men, male sex workers who can have any orientation, men engaging in these behaviours in all male settings, such as prisons, and the rich and wide array of traditional identities and terms for these men across cultures and subcultures. Transgender people born male share some biological risks with MSM, especially receptive anal intercourse, but their female gender identity places them in a different category from MSM; hence not included as subgroup in MSM [3].

Understanding the sexual behaviours of populations who are vulnerable to HIV is an important component in the fight against HIV/AIDS. In Kenya, male homosexuality is criminalized under the penal code and there is a wide spread stigma and discrimination against homosexuals. This environment has made it difficult for these people to access health services thereby increasing their vulnerability to negative health outcomes including HIV/AIDS, STI's and other health consequences. The Kenya National Aids and STI program has reported prevalence of HIV to be 18.2 among MSM in Nairobi and 11.1 percent among MSM in Kisumu. The Kenya modes of transmission had previously 
estimated that nationally, 15 percent of new infections occur among MSM and prison populations. Although homosexuality is illegal, HIV pandemic among MSM has started being addressed by government institutions.

Homosexuality has been linked to many causal factors; this study will focus on examining some of these predisposing factors. A common argument is of the inclination that homosexuality is genetic, inborn and immutable. It is however disregarded on the fact that public is likely to become more accepting of homosexuality if they are convinced it is inborn. Religious beliefs have been associated with homosexuality with fewer orthodox Jews being homosexuals and many atheists practicing homosexual. Other associated factors are culture, sexual abuse and simply as a choice [4].

Kilifi town in Kenya has 300 identified MSM Behavioural interventions such as understanding the causes of homosexuality are not widely researched in this set up. This study was aimed to explore the predisposing factors to homosexuality in an attempt to create deeper understanding necessary for crafting evidence based health interventions.

\section{Subjects and Methods}

\subsection{Research Design}

A descriptive cross-sectional study design was used in this study.

\subsection{Location of the Study}

The study was carried out in Kilifi town in Kilifi County. Located about $60 \mathrm{~km}$ north of Mombasa, Kilifi town is the main stop on the Mombasa-Malindi highway. The township has a population of 122, 899 and the HIV/AIDS prevalence stands at 7\% according to the Kenya Aids Indicator Survey of 2012. Kilifi was suitable for this study because it presents a semi-rural urban set up in the coastal region which has the highest prevalence of MSM in Kenya.

\subsection{Study Population}

Men who have sex with men in Kilifi town council and have self-identified themselves and those who are not self-identified were the target population. These included all MSM above 18years, all ethnicities and socio economic background.

\subsection{Sampling Techniques}

This study utilized non probability, snow balling sampling technique. The initial subjects were sought at MSM friendly health services and MSM self-identified groups. After sampling the initial subject, the researcher asked for a referral to other MSM.

\subsection{Sample Size Determination.}

The prevalence of homosexuality in Kilifi and indeed in Kenya is not known majorly because the practice is illegal and would therefore not want to reveal their identity. The researcher sampled all available and consenting homosexuals until there was be no new data in 3 subsequent respondents. A total of 72 men were subsequently involved.

\subsection{Pilot Study and Pretesting}

The study questionnaire, focused discussion guide and key informant structured interviews were pretested in Mtwapa town council. Ten MSM and two key informants were used.

\subsection{Data Collection Techniques}

Trained research assistants were used to collect data using self-administered open and closed structured questionnaires given to MSM, two focused group discussion with $6 \mathrm{MSM}$ each and structured key informant interviews with key people who included a health worker at Kilifi District hospital, County Aids and STI control officer, non-Governmental Organization officer, MSM representative and law enforcement officer. Data from FGD and key informant interviews were audio recorded.

\subsection{Data Analysis}

Data from questionnaires was cleaned, analysed numerically in percentages. Baseline demographic statuses like income, age religion were analysed. The researcher utilized descriptive statistics to verify for any inconsistency by keenly checking the minimum, maximum, sum, and frequencies for the variables. Further the measures of central tendency such as the mean, standard deviation were used in the process Study used Statistical package for social scientists (SPSS) version 17 to analyse data. Qualitative data was analysed thematically from the focused group discussion and key informant interview audios.

\subsection{Research Ethics Considerations}

All the relevant institutional and respondents informed verbal consents were obtained. The respondents were also assured of confidentiality.

\section{Results}

\subsection{Demographic Information}

In this study, majority of the respondents, $72.2 \%$ were aged between 21-30 years. With regards to their sexual orientation, $72.2 \%$ of the respondents indicated that they were homosexual compared to $27.8 \%$ who were bisexual. 
Concerning the respondents' marital status, most of the respondents $(63.9 \%)$ indicated they were single, $27 \%$ were married and $8.3 \%$ were divorced at the time of study.

When asked when they first developed attraction to men, $80.6 \%$ of the respondents revealed that they started being attracted to other men when they were between 11-20 years and a further $17 \%$ developed attraction even before the age of 10 years. About their educational status, $38.9 \%$ of the respondents had attained tertiary education, $29.2 \%$ had secondary school education while $31.9 \%$ were educated up to had primary school level.

The findings also indicated that majority about $53 \%$ of respondents earned less than 10,000 Kenya shillings per month. $34 \%$ indicated they earned between Kshs. $11,000-40,000$ and $13.9 \%$ were earning Ksh.41,000-90,000. Regarding the religious affiliation of the respondents, Christians were the majority at $45 . \%$ while Muslim $38.9 \%$ and only $16.7 \%$ were atheists.

Table 1. Demographic characteristics of the respondent

\begin{tabular}{|c|c|c|}
\hline Age of the respondent & $\begin{array}{c}\text { Frequency } \\
\mathrm{N}=72\end{array}$ & $\begin{array}{c}\text { Percentage } \\
\% \\
\end{array}$ \\
\hline 20 years and below & 4 & 5.6 \\
\hline $21-30$ years & 52 & 72.2 \\
\hline 31-40years & 14 & 19.4 \\
\hline $51-60$ years & 2 & 2.8 \\
\hline \multicolumn{3}{|l|}{ Sexual Orientation } \\
\hline Homosexual & 52 & 72.2 \\
\hline Bisexual & 20 & 27.8 \\
\hline \multicolumn{3}{|l|}{ Marital Status } \\
\hline Married & 20 & 27.8 \\
\hline Single & 46 & 63.9 \\
\hline Divorced & 6 & 8.3 \\
\hline \multicolumn{3}{|c|}{$\begin{array}{l}\text { Age in which the Respondents were } \\
\text { first attracted to other men }\end{array}$} \\
\hline Below 10 years & 12 & 17 \\
\hline $11-20$ years & 58 & 80 \\
\hline $21-30$ & 2 & 3 \\
\hline \multicolumn{3}{|l|}{ Level of education } \\
\hline Primary & 23 & 31.9 \\
\hline Secondary & 21 & 29.2 \\
\hline Tertiary education & 28 & 38.9 \\
\hline \multicolumn{3}{|c|}{ Average income of the respondents } \\
\hline$<10,000 \mathrm{Ksh}$ & 38 & 52.8 \\
\hline $11,000-40,000$ & 24 & 33.3 \\
\hline $41,000-90,000$ & 10 & 13.9 \\
\hline \multicolumn{3}{|l|}{ Religion } \\
\hline Christianity & 32 & 44.4 \\
\hline Islam & 28 & 38.9 \\
\hline Atheist & 12 & 16.7 \\
\hline
\end{tabular}

\subsection{Predisposing Factors/Causes of Homosexuality}

The study findings on each of the factors are discussed in the following sub-sections.

\subsubsection{Lifestyle}

Majority $62(86.1 \%)$ of the respondents describe homosexuality as lifestyle that they have developed over a long period.

\subsubsection{Inborn verses Choice}

Majority $48(66 \%)$ of the respondents believed that sexual preference is choice while $24(33.3 \%)$ of the respondents showed that sexual preference is inborn.

\subsubsection{Peer Pressure and Natural Attraction}

Majority $30(41.7 \%)$ of the respondents were influenced by their peers to have same sex orientation while $20(27.8 \%)$ indicated that they chose to have same sex orientation because they felt attracted to men naturally. A further $13 \%$ could not tell any reasons why they chose to have same sex orientation.

These findings are confirmed by FGD at Kilifi town: some of them are satisfied with living that way, it is inborn. Peer pressure is however a major contributing factor, said one health care provider. "I was wooed into homosexuality in high school by my friends in a boys boarding school...." confessed one respondent. Yet another respondent implicated correction institution like the prisons. 'When I went to prison, they forced me to have sex with them, with time I liked it, there was no option" (FGD, Kilifi town council

\subsubsection{First Same Sex Partner}

When asked about the first sexual partner, majority $50(69.4 \%)$ of the respondents mentioned their close friends. $6(8.3 \%)$ mentioned one of their relatives, $2(2.8 \%)$ mentioned a domestic workers, $12(16.7 \%)$ by other people they did not know quite well. These findings revealed that most of the people are introduced into homosexuality by friends or another second party, further emphasizing that this a socialization issue rather than biological.

\subsubsection{Upbringing and Sexual Orientation}

More than three quarters $54(75 \%)$ of the respondents believed that upbringing had nothing to do with same sex orientation while $18(25 \%)$ believed so. However, FGD findings seemed to suggest otherwise ..."At times you are in a family where all the other children are girls except you. When they go for example with their boyfriends and you are young, and you see everyone being carried around, and may be the men you are with are big and they pull you in and tell you to try it. Bad relationships in a family can cause for example you have grown in an environment where the family mistreats you until you feel that am not at the right position. So you just feel, let me just try that thing that I feel is fine for me to do." (Kilifi FGD, Kilifi town council). 


\subsubsection{Family Set up and Homosexuality}

As concerned the family set up of the respondents, majority, 38(52.8\%) were from a mother only family while $6(8.3 \%)$ single parent -father, $20(27.8 \%)$ had both parents and $6(8.3 \%)$ raised by guardian or others relatives. These findings showed that at majority came from single parent family set up of mother alone, perhaps a reason why the boy child grew pampered or surrounded by too much feminism. These findings were further echoed during an interview with the CASCO..." Being brought up in a single mother parent's family can influence one's being a MSM because of the desire to explore various things that they see happen to their sisters and mothers. Lack of freedom among children in a family, they are not engaging with anyone can make them to end up being gay" (CASCO, Kilifi county). Also the participant in a FGD stated... "Mothers pampering.... and the mother brings men into the house, the mother are careless, she is having sex and she is enjoying it and it disturbs. The next day you would call your fellow age mate, especially among kids, you would call your age mate and tell him about what was done to your mother previous day and request him to try it with you. And that is how it starts..."

\subsubsection{Childhood Sexual Abuse and Homosexuality}

When the respondents were asked whether experienced any form of sexual abuse during their childhood, 20(27.8\%) answered to the affirmative. These findings are further ascertained by MSM representative..." Sexual abuse at an early age can somehow lead a man to be MSM because one might be abused while he is young but after that he comes to think that this is not my sexual orientation and just stop but some enjoy it when they are young and grow up with it..." (Kilifi MSM representative, Kilifi town council).These findings were further confirmed by one particular case..." like my friend, his uncle influenced him into being gay because he would have sex with him since his childhood. He has been in that environment for long, at first he saw it as a bad thing but later he liked it..."

\subsubsection{Electronic Media and Homosexuality}

Majority $50(69.4 \%)$ of the respondents indicated that were watching of pornography when growing up. These findings revealed that most of the respondents had watched pornography and this concludes it may be a source of influence to gay sexual behavior. These findings are further echoed in an FGD..."watching pornography when young and in adolescent, both gay and other pornography gives one an impression that it's enjoyable to have sex with men..." (FGD, Kilifi Town Council).
Table 2. Predisposing factors to homosexuality

\begin{tabular}{|c|c|c|}
\hline $\begin{array}{l}\text { Predisposing factors to } \\
\text { homosexuality }\end{array}$ & $\begin{array}{l}\text { Frequency } \\
\mathrm{N}=72\end{array}$ & $\%$ \\
\hline \multicolumn{3}{|l|}{ Is sex orientation is a lifestyle? } \\
\hline Yes & 62 & 86.1 \\
\hline No & 8 & 11.1 \\
\hline \multicolumn{3}{|l|}{$\begin{array}{c}\text { Is sexual preference is born or } \\
\text { choice? }\end{array}$} \\
\hline Inborn & 24 & 33.3 \\
\hline Choice & 48 & 66.7 \\
\hline \multicolumn{3}{|l|}{$\begin{array}{l}\text { Reasons why the respondents chose } \\
\text { to have same sex orientation }\end{array}$} \\
\hline Naturally attracted to men & 20 & 27.8 \\
\hline Peer pressure & 30 & 41.7 \\
\hline $\begin{array}{l}\text { I don't find women attractive } \\
\text { sexually }\end{array}$ & 6 & 8.3 \\
\hline No one forced me & 6 & 8.3 \\
\hline Doesn't know & 10 & 13.9 \\
\hline \multicolumn{3}{|l|}{$\begin{array}{l}\text { Who was your first same sex } \\
\text { partner? }\end{array}$} \\
\hline My friend & 50 & 69.4 \\
\hline My relative & 6 & 8.3 \\
\hline A domestic worker & 2 & 2.8 \\
\hline Others & 2 & 2.8 \\
\hline Doesn't remember & 12 & 16.7 \\
\hline \multicolumn{3}{|l|}{$\begin{array}{l}\text { Believing that upbringing had } \\
\text { anything to do with sexual } \\
\text { orientation }\end{array}$} \\
\hline Yes & 18 & 25.0 \\
\hline No & 54 & 75.0 \\
\hline \multicolumn{3}{|l|}{ Types of family setup } \\
\hline Single parent family-mother & 38 & 52.8 \\
\hline Single parent - father & 6 & 8.3 \\
\hline Both mother and father present & 20 & 27.8 \\
\hline Raised by guardian or others & 8 & 11.1 \\
\hline \multicolumn{3}{|l|}{$\begin{array}{l}\text { Did you experience any sort of } \\
\text { sexual abuse in childhood? }\end{array}$} \\
\hline Yes & 20 & 27.8 \\
\hline No & 52 & 72.2 \\
\hline \multicolumn{3}{|l|}{$\begin{array}{l}\text { Were you exposed to pornography } \\
\text { in your childhood? }\end{array}$} \\
\hline Yes & 50 & 69.4 \\
\hline No & 22 & 30.6 \\
\hline
\end{tabular}




\subsection{Role Played by Respondents in Homosexual Relationship}

Table 3 presents information on role played by respondents. Majority 42(58.3\%) of the respondents indicated that they played a king role while $30(41.7 \%)$ played a queen role. Most of the respondents played the king role, which is a giver or inserter and the rest were the recipients, who played the "females" in these relationships.

Table 3. Role played by respondents in homosexual relationship

\begin{tabular}{|c|c|c|}
\hline Role played & Frequency & Percentage \\
\hline King & 42 & 58.3 \\
\hline Queen & 30 & 41.7 \\
\hline Total & 72 & 100.0 \\
\hline
\end{tabular}

\section{Discussion}

The study has generally showed that homosexuality is a practice one chooses to engage in voluntarily or as a result of socialization. Majority of the respondents indicated choice as being the reason they are homosexuals with few indicating that it is inborn. These findings concurs with those of a study done in United States of America [5], which showed that homosexuality is not inborn or biological as twin studies have failed to prove so. In this study there was very minimal family history of gay in the homosexual individual's family that further strengthens the fact that this behaviour is not inborn. Rather this is a sexual orientation one learns or gets socialized into at some point in life. In this study, $72.2 \%$ of homosexuals were in the age bracket of 21-30 years, with most having realized their sexual orientation between the ages of 11-20 years. Furthermore, majority of the respondents said homosexuality is a lifestyle, meaning it is a learned behaviour. Robert [6] concluded that homosexuality is a choice. Making a choice is a decision in the mind that too often originates in the heart from feelings. However, laws and moral standards are not set in place based on feeling or emotions.

However this study has failed to prove that religion has a role to play in one being a homosexual where atheists are believed to be majority in the homosexuality. In this study, only $16.7 \%$ of respondents were atheists. This therefore differs with the findings of Berin [7] on his study in the United States on whether religion affects sexual orientation where he concluded that most homosexuals are atheists.

Child upbringing has a lot to do with individual turning out to be homosexual in the future; $(52.8 \%)$ of the respondents were raised by single mothers, who unknowingly pampered them too much or sisters who over feminized the boy child and never allowed them to assume masculine roles or engaged in sexual activities with different opposite sex members and the growing boy child found out by default hence quest to find out more. These findings tally with those of James [1] in his study on upbringing and homosexuality, which indicated that females who include mothers, sisters and the extended female family members, teachers, baby sitters and others can wound a boy when he is growing up in a variety of ways. Females often overwhelm the growing boy with too much smothering attention and love. They may overprotect him, leaving him feeling incapable and emasculated. The boy may grow up being criticized by females for his weaknesses, causing lasting feelings of shame, self-doubt and insecurity. Feminization and family castellation had a role in some being homosexuals as affirmed by the FGD .." my cruel mother used to mistreat my dad, I grew up with a dislike for women due to that experience".." my sister would bring men in the house, have sex and make some noises and I envied how those men were treating her.." (FGD, Kilifi Town Council). These findings concur with a study done by Bayne and Parsons [9] on role of upbringing in homosexuality, where they stated that castellation in childhood and poor mother/ father relationships can lead men to become oppositional in their relationships and tend to push women away or reject them. They have feelings of dislike, resentment, disgust or even hatred towards women. Some MSM are completely conscious and blatant about their dislike for females.

Peer pressure stands out as one of the major causes of homosexuality with majority of the respondents being introduced to this behaviour by friends in adolescent years or few cases in imprisonment. These findings concur with those of another study [5] which suggested that homosexual orientation develops as a result of psychological and environmental influences and experiences when the boy is growing up.

Sexual abuse when growing up is another cause of homosexuality, where the boy was abused by a male or sodomised at a young age. In this study, $(27.8 \%)$ of the respondents were abused when growing up. These findings concur with those of Bern [9] in his study on bad experiences of boy child with men when growing up and its role in homosexuality, these experiences may be abuse (physical or sexual, harassment, rejection or non-inclusion. Boys who develop needy relationships with males long for male intimacy, long to be taken care of by males and they become dependent of male attention, affection and approval.

Majority of the respondents (69.4\%) watched pornography when growing up and this had a role in their homosexual orientation, findings which agree with those of Bailey [11] in his study on role of sexual conditioning to homosexuality. He stated that in the highly sexualized context of pornography, boys may confuse feelings of curiosity, envy, awe and wonder with sexual arousal. Once learned, pleasurable sexual behaviors are reinforced and boys continue engaging in them. When a boy becomes sexually aroused by male images out of sexual exposure, it may cause him to belief or confirm to him that he is homosexual or gay. This then becomes learned part of his identity. 


\section{Conclusions and Recommendations}

\subsection{Conclusions}

Homosexuality is not inborn or genetically inherited. Sexual orientation is a lifestyle that is cultivated in young minds through family, friends, and relatives, electronic media and corrective institutions like prisons. It represents a boy child struggling to find his way in the confused and malfunctioning family and social institutions.

\subsection{Recommendations}

There is need to consciously and openly discuss the issues of homosexually especially in a conservative society like Kenya, if any meaningful step is to be made in mitigating the challenges homosexuals face. Community involvement and sensitization would be important in reducing the number of boys who convert to homosexuality at some point in life. Future studies are recommended to clarify the dangers of such practice such as rectal cancers, HIV and the potential renal problems affecting both partners (11). Such alarms might limit the homosexuality among youths.

\section{Acknowledgements}

The authors would like to acknowledge colleagues at the department of Medical Services and School of Health Sciences, Kirinyaga University College for both the technical and moral support received in the course of this study.

\section{REFERENCES}

[1] James, William H. "Two hypotheses on the causes of male homosexuality and paedophilia." Journal of biosocial science 38.06: 745-761. 2006

[2] Karanja, C. Factors contributing to prevalence of homosexuality in private boarding secondary schools: A case of Kiambu County, Kenya. Journal of Public Med, 50(3), 134-140.2014.

[3] Bily, C. A. Homosexuality: opposing viewpoints. Detroit: Greenhaven Press. 2009.

[4] Association of Nurses. Changing Hostile Attitudes toward Homosexuals in a Region Facing One of the Highest Incidences of HIV/AIDS. Journal of the Association of Nurses in AIDS Care, 14(1), 86. 2003.

[5] Ferrebe, A. Literature of the 1950s: good, brave causes. Edinburgh: Edinburgh University Press. 2012.

[6] Robert Goetz. Overcoming Homosexuality. New York: Macmillan Publishing Co. 2004.

[7] Adam, Barry D., Alan Sears, and E. Glenn Schellenberg. Accounting for unsafe sex: interviews with men who have sex with men. Journal of sex research h. 37, 24-36. 2002.

[8] James, William H. "Two hypotheses on the causes of male homosexuality and paedophilia." Journal of biosocial science 38.06: 745-761. 2006.

[9] Bayne and Parsons Human Sexual Orientation. The Biologic Theories Reappraised. pp 236. 2005,

[10] Bailey, J. Michael and Zucker, Kenneth. Childhood Sex-Typed Behavior and Sexual Orientation: A Conceptual Analysis. Developmental Psychology, vol. 31, (No.1). (2005). Obtained from http://borngay.procon.org/

[11] Hegazy A. Repetitive Anal Intercourse as a Potential Risk for Renal Failure. Academia Anatomical International, 1(1):1-2. 2015. 